\title{
MYCOSIS FUNGOIDES - A CASE REPORT
}

\author{
ALI CM ${ }^{1}$, AKHTER N ${ }^{2}$, KARIM E $^{3}$, RAHMAN M ${ }^{4}$

\begin{abstract}
:
A man of 42 years presented with multiple nodulo-ulcerative lesions on the face and scalp for 1 month. The lesions were preceded by multiple erythematous scaly patches and plaques for last 4 years with palmoplantar hyperkeratosis for the same duration. On general examination, there was universal erythema and generalized lymphadenopathy. Diagnosis was established by detailed history, thorough physical examination and relevant laboratory investigation including histopathology and immunophenotyping. Though he had the classical features, the psoriasis-like presentation at the outset resulted in delay in diagnosis. We also presented the prognostic factors worsening his conditions.
\end{abstract}

Key words: Mycosis fungoides, lymphoproliferative disorder, nodulo-ulcerative lesions.

J Dhaka Med Coll. 2012; 21(2) : 238-241.

\section{Introduction:}

Mycosis fungoides (MF), a low-grade lymphoproliferative disorder, is the most common type of cutaneous T-cell lymphoma. Typically, neoplastic T cells localize to the skin and produce patches, plaques, tumours or erythroderma. ${ }^{1}$ Diagnosis of MF is based on a combination of clinical presentation; histopathology and gene rearrangement. ${ }^{2}$ None of these factors exclusively determines the diagnosis. Histologically, MF is characterized by the presence of large atypical lymphocytes, a lymphocytic infiltrate in the papillary dermis and thickened collagen fibres. ${ }^{3}$ Molecular biology has improved the diagnostic accuracy. Nevertheless, clinical experience is of substantial importance, as MF can resemble wide variety of skin diseases.

\section{Case report:}

A 42 year-old male patient (Fig.1) from Dagonbhuiyan, Feni presented to us with multiple erythematous scaly patches and plaques with palmoplantar hyperkeratosis for 4 years. The lesions were associated with generalized pruritus for the same duration. For this he consulted with dermatologist and investigated thoroughly including biopsy followed by histopathology, which was compatible with psoriasis and treated accordingly but he was not improved. Later on,

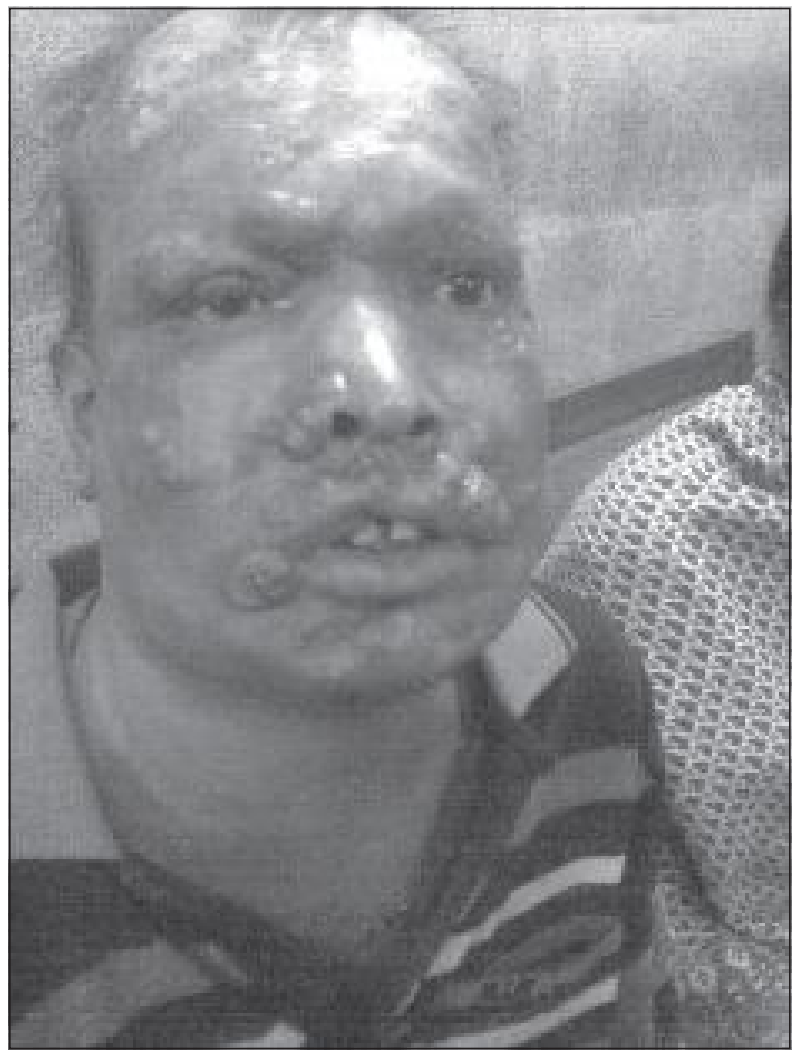

Fig.-1: Multiple nodulo-ulcerative lesion in the face.

1. Dr. Chowdhury Mohammad Ali, Professor and Head, Department of Dermatology \& Venereology, Dhaka Medical College \& Hospital, Dhaka.

2. Dr. Nasreen Akhter, Department of Dermatology \& Venereology, Dhaka Medical College Hospital, Dhaka.

3. Dr. Enamul Karim, Department of Dermatology \& Venereology, Dhaka Medical College Hospital, Dhaka.

4. Dr. Mahbubur Rahman, Department of Dermatology \& Venereology, Dhaka Medical College Hospital, Dhaka. Correspondence: Dr. Chowdhury Mohammad Ali, Professor and Head, Department of Dermatology \& Venereology, Dhaka Medical College \& Hospital, Dhaka. 
he developed multiple erythematous, painless nodules on face and scalp for last 1 month. Some of those became ulcerated later on. He had extensive erythema and scaling on the whole body with severe pruritus for last 20 days. He also had low grade irregular fever and anorexia and weakness for last 20 days. He had a history of atopy since childhood.

On examination, he was moderately anaemic and had mild edema. He had generalized lymphadenopathy involving cervical (Fig. 2), axillary, and inguinal region. They were of variable sizes, mobile, discrete, with firm to hard consistency. Physical examination revealed swollen face with multiple discrete and

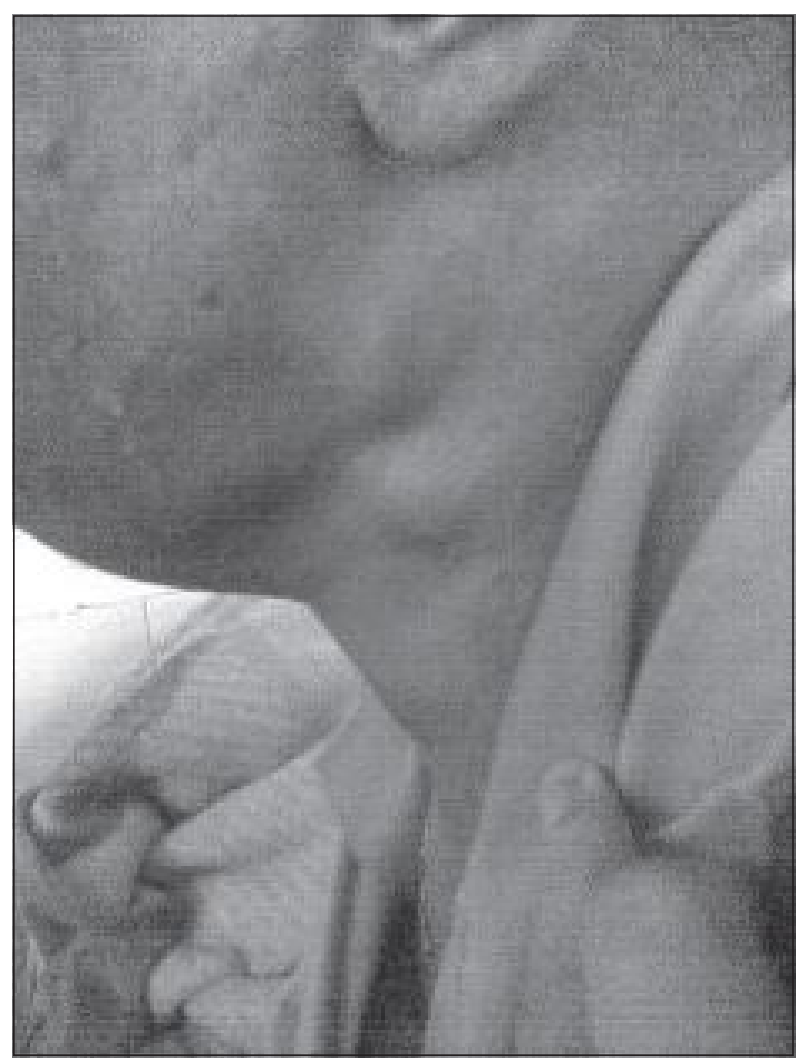

Fig.-2: Lymphadenopathy in anterior group of cervical lymph nodes.

confluent nodular and nodulo-ulcerative lesions on the face and scalp, especially over nose, eyebrows, forehead and upper lip (Fig. 1). These were erythematous, shiny, soft, tender, smooth-surfaced and free from underlying structure. The ulcers were of variable sizes, irregular margin, sloping edges with uneven surface and indurated base and covered with unhealthy slough. There was universal erythema. Diffuse hair loss was noted over scalp, eyebrows, trunks and extremities. Nails were dull, rough, thickened and dystrophic. Complete blood count showed normal finding except haemoglobin conc. $9.5 \mathrm{gm} / \mathrm{dl}$ and ESR45 $\mathrm{mm}$ in $1^{\text {st }}$ hour, peripheral blood film showed normochromic normocytic anemia, routine urine, RBS, X-ray chest, ultrasonogram of whole abdomen, liver and renal function test were normal, VDRL-non reactive, TPHAnegative, slit skin smear for AFB-negative, ICT for kala-azar-negative. Histopathology (Fig. 3) and immunophenotyping was suggestive of MF.

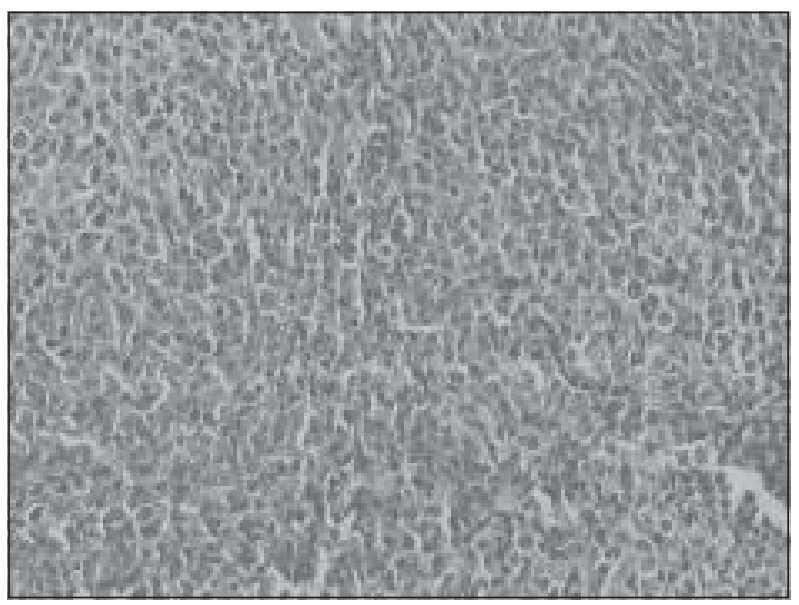

Fig.-3: Histopathology of the psoriatic lesion in high magnification.

In immunoshistochemistry all neoplastic lymphoid cells in the dermis are CD3 positive (Fig. 4) and those are negative for CD20 (Fig. 5).

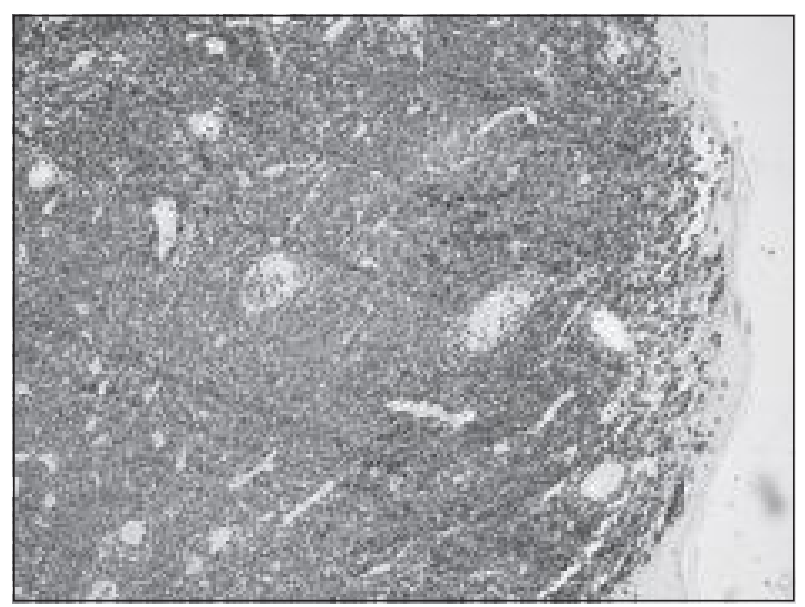

Fig.-4: Immunophenotyping of the lesion showing feature suggestive CD3 positive. 


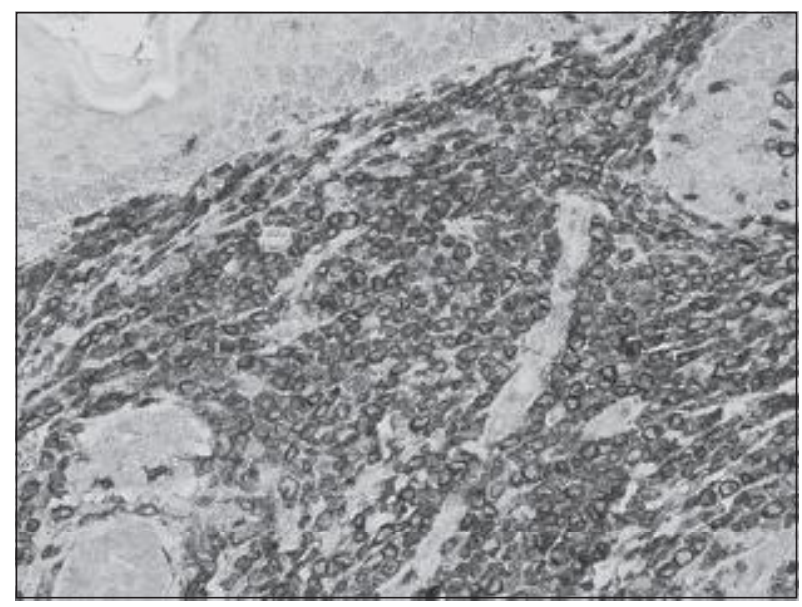

Fig.-5: Immunophenotyping of the lesion showing feature suggestive CD2O negative.

\section{Discussion:}

MF is a neoplasm of memory helper T- cell which initially presenting in the skin. ${ }^{4} \mathrm{MF}$ has a plethora of clinicopathological manifestations from the classical Alibert-Bazin disease to many 'atypical' forms. ${ }^{1}$ The incidence of MF is 1 in 300,000 per year. ${ }^{5}$ Men are more often affected than women (male: female ratio, 2: 1). MF affects adults most frequently, usually in the fifth to sixth decade, although any age group may be involved. ${ }^{6}$

A number of case control studies have investigated the possibility of environmental agents precipitating and aggravating early CTCL. Other studies recorded that patient with atopic dermatitis appear to be at increased risk for the development of MF, suggesting that persistent stimulation of T-cells may lead to development of a malignant clone. Our patient had history of atopy since his childhood.

In early stages of MF the disease starts with non-specific scaly lesions of varying sizes resembling various inflammatory dermatoses. In our case, the plaques resemble psoriasis at first. Pruritus is common and often severe. Our case presented with mild to moderate generalized pruritus.

It usually takes several years until the patches progress into plaques and tumours, which may then ulcerate. At tumour stage, the surface of the nodules is soft on palpation which distinguishes the lesions from metastases of solid carcinomas. The nodules of our patient were soft, dome shaped, erythematous and ulcerated. Lymph node and internal organs may become involved in the later stages of $\mathrm{MF}$, which is usually associated with an aggressive clinical course. ${ }^{4,7}$ our patient has generalized lymphadenopathy.

In very early stages (premycotic stage) the histologic picture is non-specific, characterized by a mild perivascular infiltrate in the upper dermis containing no atypical lymphocytes and epidermotropism. Early MF can produce almost all patterns used for diagnosing inflammatory skin diseases. This may be the reason for misdiagnosing our case as psoriasis at earlier. The histological findings become diagnostic in the late patch stage or the early plaque stage ('thin plaque stage'), when a denser infiltrate is present, with lymphocytes lining up in the basal layer and showing single-cell epidermotropism ${ }^{8}$.

The typical phenotype of the small cerebriform cells is $\mathrm{CD} 2+, \mathrm{CD} 3+, \mathrm{CD} 5+, \mathrm{CD} 4+, \mathrm{CD} 45 \mathrm{Ro}^{+}$, CD8-, CD25-(rarely CD25+), TCR ,CD36-. Our case was $\mathrm{CD} 3+$ and $\mathrm{CD} 20$ - which indicate cutaneous $\mathrm{T}$ cell lymphoma and negative B cell immunophenotype marker. Other markers could not be done due to financial constraint and also for unavailability in Bangladesh. Patients with early stages have an excellent prognosis with survival similar to that of an age, sex, and race matched population ${ }^{9}$. Factors indicating poor prognosis are advanced stage and age above 60 years when extracutaneous involvement or transformation into high grade lymphoma occurs. Lymphadenopathy, tumours or cutaneous ulceration are cardinal prognostic factors. No patient died without having developed one of them. Patients with all three (in any order) survive a median of one year. Our case was advance age with all three bad prognostic criteria died 3 months after diagnosis with symptomatic treatment.

\section{Conclusion:}

Knowledge of cutaneous lymphoma is advancing. According to Kotz et al. ${ }^{10}$, 'In every chronic disease resistant to treatment lymphoma has to be considered'. Therefore, if 
lymphoma is suspected then the diagnosis must be confirmed by clinical, histological and molecular examinations perhaps repeated in the course of the disease. Once a lymphoma has been diagnosed a consequent follow up is also required to detect possible recurrence or manifestation of other associated conditions ${ }^{10}$. So, the resistant eczematous or psoriasiform lesions should be considered as one of the differential of early mycosis fungoides.

\section{References:}

1. Nashan D, Faulhaber D, Ständer S, Luger TA, Stadler R. Mycosis fungoides:A Dermatological masquerader. Br J Dermatol 2007; 156(1): 1-10.

2. Willemze R, Meijer CJ. Rationale of a new classification for the group of primary cutaneous lymphomas. Semin Cutan Med Surg 2000; 19(2): 71-7.

3. Naraghi ZS, Seirafi H, Valikhani M, Farnaghi F, Kavusi S, Dowlati Y. Assessment of histologic criteria in the diagnosis of mycosis fungoides. Int J Dermatol 2003; 42(1): 45-52.

4. Kazakov DV, Burg G, Kempf W. Clinicopathological spectrum of mycosis fungoides. J Eur Acad Dermatol Venereol 2004; 18(4): 397-415
5. James WD, Berger TG, Elston DM. Cutaneous lymphoid hyperplasia, cutaneous T- cell lymphoma, other malignant lymphomas and allied diseases In: Andrews' diseases of skin clinical dermatology. $9^{\text {th }}$ ed. Philadelphia: Saunders Elsevier; 2006.

6. Kim YH, Hoppe RT. Mycosis fungoides and Sézary syndrome. Semin Oncol 1999; 26(3): 276-89.

7. Jaffe ES, Harris NL, Stein H, Vardiman JW. eds. World Health Organization classification of tumours. Pathology and genetics of tumours of haematopoietic and lymphoid tissue. Lyon: IARC Press; 2001.

8. Burg G, Dummer R, Dommann S, Nestle F, Nickoloff B. Pathology of cutaneous T-cell lymphoma. Hematol Oncol Clin North Am 1995; 9(5): 961-95.

9. Diamandidou E, Colome M, Fayad L, Duvic M, Kurzrock R. Prognostic factor analysis in mycosis fungoides/Sézary syndrome. J Am Acad Dermatol 1999; 40(6 Pt.1): 914-24.

10. Kotz EA, Anderson D, Thiers BH. Cutaneous Tcell lymphoma. J Eur Acad Dermatol Venereol 2003; 17(2): 131-7. 